\title{
Spatial and spatiotemporal occurrence of human visceral leishmaniasis in Adamantina, State of São Paulo, Brazil
}

\author{
Marisa Furtado Mozini Cardim ${ }^{[1]}$, Carolina Portugal Vieira ${ }^{[2]}$ \\ and Francisco Chiaravalloti-Neto ${ }^{[3]}$
}

[1]. Faculdades Adamantinenses Integradas, Adamantina, São Paulo, Brasil. [2]. Curso de Graduação em Enfermagem, Escola de Enfermagem, Universidade de São Paulo, São Paulo, São Paulo, Brasil. [3]. Departamento de Epidemiologia, Faculdade de Saúde Pública, Universidade de São Paulo, São Paulo, São Paulo, Brasil.

\begin{abstract}
Introduction: Several municipalities of the Western region of the State of São Paulo have been affected by human visceral leishmaniasis (HVL), including the City of Adamantina, where the first autochthonous cases occurred in 2004. Therefore, this study aimed to describe the spatial and spatiotemporal occurrence of HVL in Adamantina. Methods: Secondary data regarding the occurrence of HVL in Adamantina between 2004 and 2011 were used. Incidence, mortality, and case fatality rates were calculated. We used local empirical Bayesian incidence rates to represent the occurrence of the disease in the census sector of the city. The existence of spatial and spatiotemporal clusters of cases was evaluated using scan statistics. In situ observation was performed to assess the socioeconomic and environmental characteristics of the areas with medium and high incidences. Results: Adamantina reported cases in $70 \%$ of its census sectors. No differences were observed between sexes. The group aged 0-4 years presented the highest incidence and mortality rates, and the group aged 40-59 years presented the highest fatality rate. We detected a spatiotemporal cluster, which coincided with the commencement of the endemic in the city. Conclusions: The individuals most affected by the disease were children. The disease was present in areas with better and worse socioeconomic conditions. The use of spatial analysis techniques was important to achieve the study objectives.
\end{abstract}

Keywords: Human visceral leishmaniasis. Epidemiology. Spatial analysis. Spatiotemporal analysis.

\section{INTRODUCTION}

Visceral leishmaniasis (VL) is a zoonotic disease with systemic involvement. In the Americas, the transmission cycle is characterized by the bite of a female sand fly, Lutzomyia longipalpis, infected with Leishmania infantum chagasi ${ }^{(1)}$.

Until the 1980s, VL was considered a rural disease in Brazil. However, factors such as migratory movements, disorderly occupation of the city outskirts and vector adaptation to the human environment were responsible for the change in the disease epidemiologic profile ${ }^{(2)}$. According to the Ministry of Health, 21 federal units of the country have reported autochthonous cases of human visceral leishmaniasis (HVL), both in rural and urban environments ${ }^{(3)}$.

In São Paulo, the first autochthonous case of HVL was reported in 1999 in the City of Araçatuba ${ }^{(4)}$. Since then, a rapid expansion of the disease to cities in the Araçatuba region and neighboring regions was observed, which occurred in Adamantina in $2004^{(5)}$.

Corresponding author: Prof. Francisco Chiaravalloti-Neto. Depto. Epidemiologia/ Faculdade de Saúde Pública/USP. Av. Dr. Arnaldo 715, 01246-904 São Paulo, São Paulo, Brasil.

Phone: 5511 3061-7920

e-mail: franciscochiara@usp.br

Received 3 Jul 2015

Accepted 12 November 2015
The objectives of this study were to describe the spatial and spatiotemporal occurrence of cases of and deaths from HVL in Adamantina and identify and characterize the risk areas for the occurrence of autochthonous cases.

\section{METHODS}

This study is a descriptive and ecological investigation of the HVL cases that occurred in Adamantina between 2004 and 2011. The city is located in the Western region of São Paulo, $614 \mathrm{~km}$ from the capital and $124 \mathrm{~km}$ from Araçatuba. According to the population census of the Brazilian Institute of Geography and Statistics [Instituto Brasileiro de Geografia e Estatística (IBGE)] in 2010, the city covers an area of $411.385 \mathrm{~km}^{2}$, has a population of 33,797 inhabitants $(31,948$ in the urban areas and 1,849 in the rural areas), and has an average of 2.95 people per household. The city has $98 \%$ of its roads paved and $99 \%$ of its households with basic sanitation, and its economy is based on agribusiness. The city is part of the administrative region (AR) of Marilia, which is in the vicinity of the AR of Araçatuba and Presidente Prudente. Adamantina is a host city of the microregion (a subdivision of the ARs in the State of São Paulo) with the same name, the microregion (MR) of Adamantina (Figure 1), which is composed of 10 cities.

Data on autochthonous HVL cases from 2004 to 2011 were used and were obtained from information provided by 


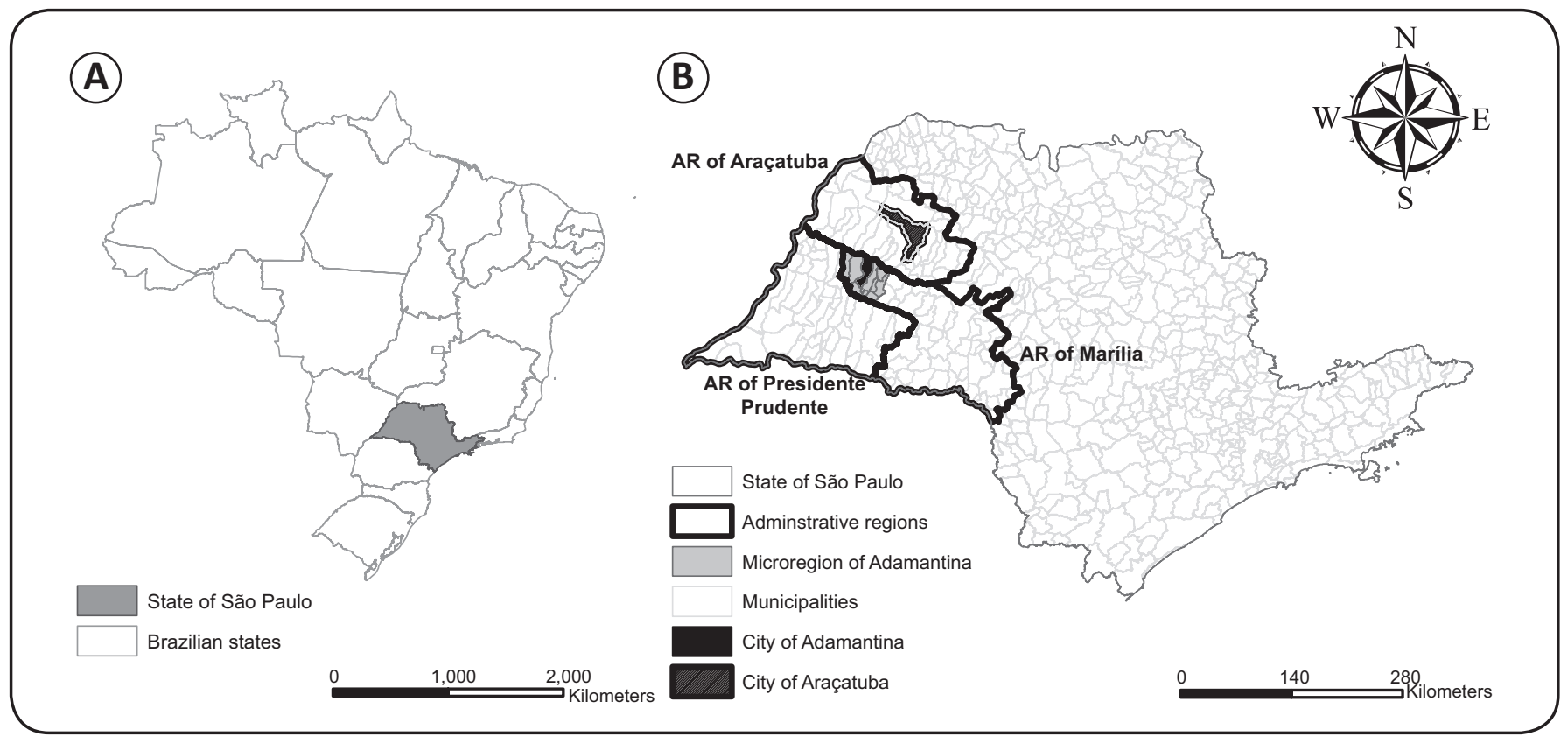

FIGURE 1 - A. Map of Brazil and of the State of São Paulo. B. Map of the municipalities of the State of São Paulo with the location of the City of Adamantina and Araçatuba; the microregion of Adamantina; and the administrative regions of Araçatuba, Marília and Presidente Prudente. AR: Adminstrative regions.

the Epidemiological Surveillance of Adamantina Secretariat of Health and by the Epidemiological Surveillance Center (Prof. Alexandre Vranjak of the São Paulo State Secretariat of Health). Information regarding the population of Adamantina during the study period, divided according to census tract, sex, and age, was used. The following data of the affected population were used: age, sex, date of symptom onset, and occurrence of death or survival. To evaluate the characteristics of land use in the affected census sectors, visits were arranged, and the characteristics of households and empty land areas, numbers of vacant lots in the census sector and origin of population (whether rural or urban area), and the maintenance habits of the external area of the household were investigated.

The city georeferenced census sector map (Lat/Long SAD69) and population information were obtained from IBGE. Adamantina is divided into 85 census sectors (67 urban and 18 rural sectors). To develop the study and elaborate maps, rural areas were eliminated (17 in all). Among the urban sectors, 10 were eliminated because they were not populated through 2011. Sectors with a small number of inhabitants were also aggregated into larger neighboring sectors; sector number 80 was added to 42 ; sector 40 was added to 44 ; and sectors 51 , 79 , and 82 were added to sector 83 . The study excluded cases corresponding to relapses.

The cases of HVL with residence in the urban area of the city were manually allocated on an address map elaborated through visits to case residences. The boundaries of the census sectors were drawn on the map of the addresses, with information from the 2010 census, which yielded information regarding the census sector to which each case of HVL belonged.
Human visceral leishmaniasis incidence and mortality rates, standardized by age, were calculated (total and by sex) for the entire county across the study period. Incidence and mortality rates by sex and age group were calculated, also considering the entire city and study period. The overall case fatality rates by sex and age group were obtained for the entire period and city. Based on the location of HVL cases in urban census sectors, the incidence rates, standardized by age, were obtained for each sector, annually and for the entire study period. We used the population of the entire City of Adamantina in 2010 as the standard population to standardize incidence rates.

The census sectors of Adamantina have small populations (1,000 inhabitants on average), causing random fluctuations in the HVL incidence rates. To avoid this problem, we recalculated the incidence rates using the local empirical Bayesian approach ${ }^{(6)(7)}$. Since the incidence rates were standardized by age (and our idea was to maintain it), it was necessary to recalculate the number of HVL cases, multiplying, for each census sector, its standardized incidence rate (divided by 100,000 ) by the total number of its inhabitants. Thus, we obtained the expected number of HLV cases for each census sector, considering that it would have the same age structure of the standard population. These procedures were conducted using the TerraView 4.2.2 software that utilizes the number of cases and the population of each census sector to calculate the local empirical Bayesian incidence rates. We also obtained the Bayesian incidences for each census sector, annually and for the entire study period.

To evaluate the occurrence of HVL annually, we generated thematic maps showing the years of the occurrence of the first(s) case(s) of HVL and the corresponding annual Bayesian incidence rates, based on urban census sectors. 
To identify the existence of spatial and spatiotemporal clusters of HVL cases, scan statistics available in the SaTScan 9.3.1 program were used. For the first case, the software imposed circular windows in each point of the map (centroids of each census sectors) that varied from size zero until a specified maximum size (50\% of the exposed population). The program, that was based on a likelihood concept, chose the clusters and assigned $p$-values for them ${ }^{(8)}$. To identify spatial clusters, we used the discrete Poisson model, a time period of January 2004 to December 2011, non-occurrence of geographical overlap, circular shape, number of replications equal to 999 , and level of significance of 0.05 .

For the spatiotemporal clusters, the software imposed cylindrical windows in each point of the map, with the circular base representing the space and the cylinder height representing the time. This volume varied from zero to a specified maximum size (area of the base comprising 50\% of the total population and the cylindrical height comprising $50 \%$ of the study period). The clusters are chosen by the program, using the likelihood concept, and p-values were attributed for them ${ }^{(8)}$.

In addition to these conditions imposed in order to identify spatial clusters, in the analysis to identify spatiotemporal clusters, we also considered precision time in months. Both analyses were performed by controlling for the occurrence of cases by the size of the census sector population and by their age and sex distribution ${ }^{(8)}$. The results of the spatial analysis are presented in thematic maps built in ArcGIS 10.0.

\section{Ethical considerations}

This study was approved by the Research Ethics Committee of the Medical School of São José do Rio Preto (Opinion number 381/2009).

\section{RESULTS}

Adamantina was the first City in the MR of Adamantina and the second in the AR of Marília to register autochthonous cases of HVL; 83 cases were confirmed from 2004 to 2011. Of these, 81 were reported from 38 of the 54 urban census sectors, and 2 from the countryside.

Figure 2A shows the annual incidence rates of HVL; the highest rates occurred at the beginning of the period under study, in 2005 and 2006 (year of peak incidence). From 2007 onwards, the incidence rates dropped, which settled at approximately 25 cases per 100,000 inhabitant-years. The incidence rates were higher in male patients than in female patients for some years; in the other years, this trend reversed. On average, there were no relevant differences between the observed values.

The most affected age group was 0-4-year-old children, with the incidence rate being 4-8 times higher than the rates in the other age groups. Mortality rates were also higher for individuals in this group, and the highest fatality rates occurred in people aged between 40 and 59 years (Figure 2B).

Figure 3A shows the incidence rates for the entire study period according to urban census sectors. Of all the sectors,
$16.3 \%$ reported no cases of HVL. Among the sectors that registered cases of HVL (83.7\%), the highest value was 101.4 cases per 100,000 inhabitant-years. Figure 3B shows the urban census sectors according to the date of occurrence of the first case(s) of HVL. The years 2005 and 2006 demonstrated the largest numbers of sectors with the registration of the first HVL cases, coinciding with the years of highest incidence rates throughout the study period. Additionally, from 2007 onwards, the speed of dissemination of the disease to other census sectors was reduced.

Figure 3C presents the Bayesian incidence rates also for the entire study period; after the correction of the random fluctuation of the incidence rates, the Bayesian incidence rates varied from 10.8 to 89.2 cases per 100,000 inhabitant-years, i.e., all census sectors presented incidences above zero and the maximum incidence value diminished.

The field observation conducted in this study showed differences between socioeconomic and environmental characteristics of the census sectors, particularly in those with medium and high incidence rates, considering both the incidence rates and the Bayesian incidence rates. Sector 17, located in the extreme southeast region of the city, has a low income and low education population and many vacant lots in precarious conditions. Sectors 8 and 62, located in the downtown area, underwent an older urbanization process, have few vacant lots, have edifications in large well-maintained walled plots of land, and have populations that can be characterized as middle class. Sectors 10, 13, 30 and 37, which are located more peripherally, have lower middle class populations; the vast majority comes from the countryside, and the houses are built on large plots of land. There are also many vacant lots (Figures 3A and $\mathbf{3 C}$ ).

Figure 4 shows the HVL Bayesian incidence rates distributed by census sectors and year throughout the study period. The years 2005 and 2006 distinguished themselves in terms of the number of sectors with rates above 87.0 cases per 100,000 inhabitant-years. All parts of the city presented HVL cases, and the high incidence rates were identified in both the periphery and center of Adamantina.

The purely spatial analysis conducted for the entire study period did not identify significant spatial clusters. Meanwhile, we detected a significant spatiotemporal cluster of HVL cases $(\mathrm{p}=0.0045)$ occurring between January 2005 and December 2006, encompassing the most peripheral eastern and central part of town. A total of 18 census sectors and $23 \mathrm{HVL}$ cases were included in the cluster, yielding a relative risk of 4.0; specifically, the disease incidence in the cluster was nearly three times greater than its effect in the outside area (Figure 5).

\section{DISCUSSION}

After the occurrence of the first autochthonous cases of HVL in 1999 in Araçatuba, Birigui, a city that borders Araçatuba and belongs to the AR of Araçatuba, was the second in the State of São Paulo to register the disease, also in 1999. The connection from inside this region to other regions of the state is principally 

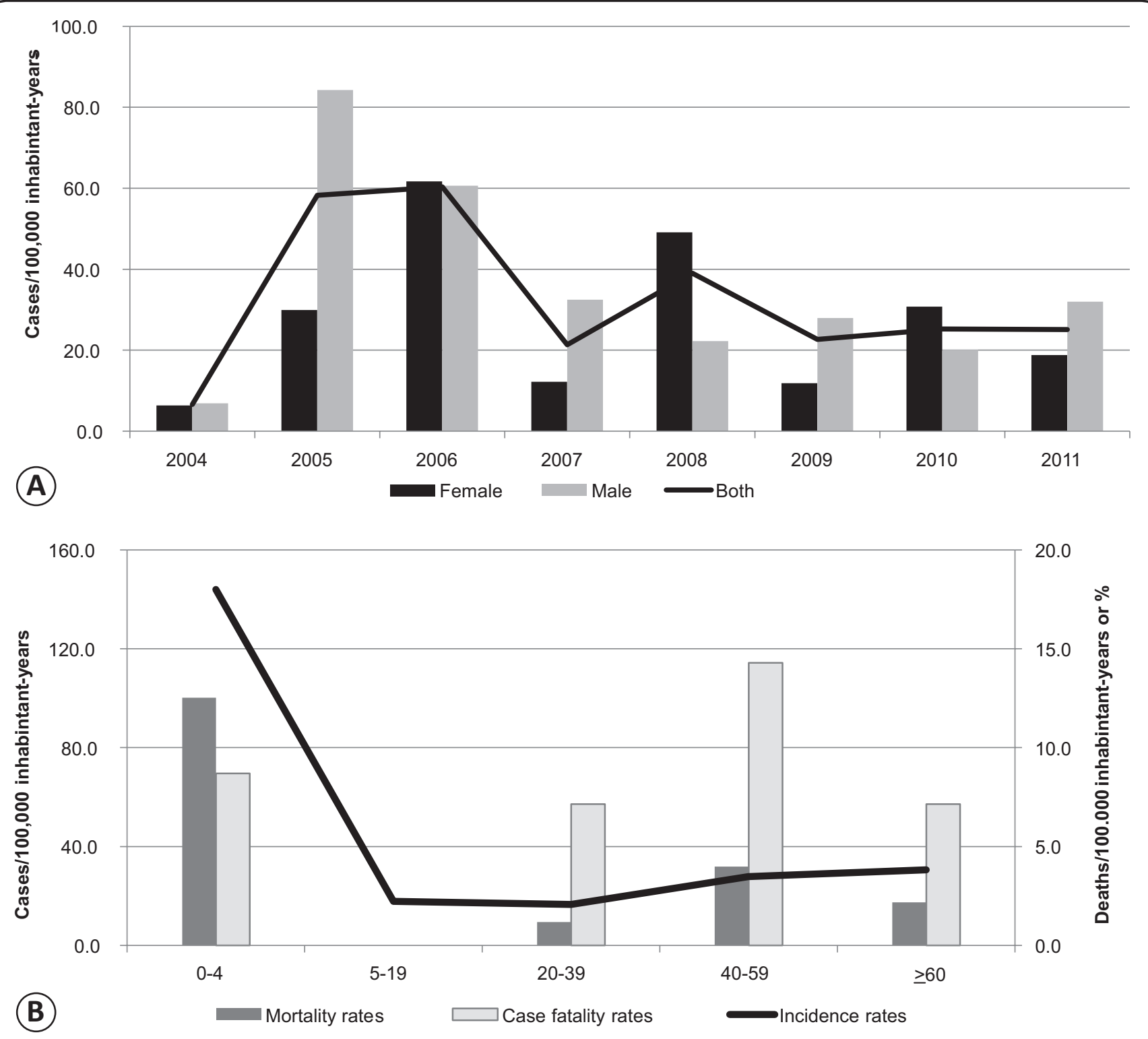

FIGURE 2 - A. Overall and sex-based, age standardized, annual incidence rates of HVL. B. Incidence, mortality, and case fatality rates of HVL, by sex, age group, and overall (age standardized). Adamantina, State of São Paulo, Brazil, 2004-2011. HVL: human visceral leishmaniasis.

established by the Marechal Rondon highway, a radial road on which there is great movement of people and goods. Consistent with the importance of this highway, we observed that the dispersion and expansion of HVL followed from northwest to Southeast, along the route linking the cities that coincides with the trajectory of the Marechal Rondon highway ${ }^{(5)}$.

This expansion of HVL also occurred along a second axis, running both North and South and following the course of transversal highways and other radial roads, reaching cities of other regions located to the north and South of the AR of Araçatuba $^{(5)}$. This pattern was observed in Adamantina, a city located to the South of Araçatuba, which reported the first autochthonous cases of HVL in 2004. Adamantina is a center of higher education that attracts a large amount of students primarily of the MR of Adamantina and also of the regions of
Marília, Presidente Prudente, and Araçatuba daily, suggesting that the occurrence of HVL in the city originated in, or at least is related to, the region of Araçatuba, endemic since 1999(9).

This city was the first in the MR of Adamantina that was affected by the disease, and during the period of 2005 to 2010 , all other cities of this microregion, except the Cty of Pracinha, were affected by the disease. Until currently, Pracinha did not have confirmed cases of $\mathrm{HVL}^{(9)}$. This situation is similar to that of other microregions in the State of São Paulo that already have reported the disease (i.e., the first city to report HVL cases has been the host city of each microregion). The 5 ARs of the state with $\mathrm{HVL}^{(5)}$ have 7 microregions without the disease and 16 with it. Of these, 10 regions $(62.5 \%)$ reported the first occurrence of HVL in the host city of each microregion ${ }^{(9)}$. 

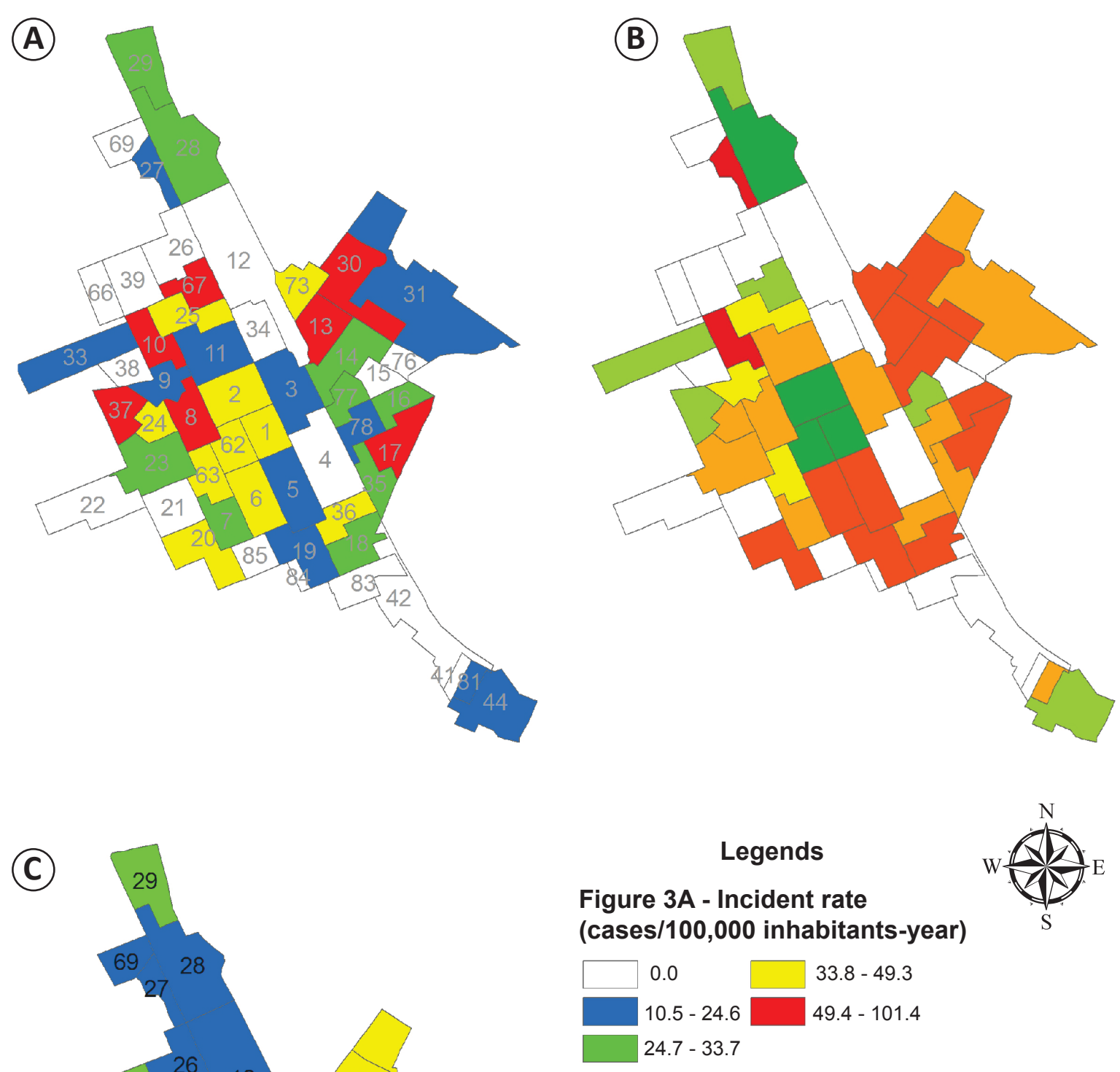

Figure 3B - Year of the occurrence of the first case (s) (number of census sector

\begin{tabular}{|l|l|}
\hline & Withour cases (17) \\
\hline & 2007 (3) \\
$2004(2)$ & 2008 (6) \\
2005 (11) & 2010 (4) \\
$2006(11)$ & \\
\hline
\end{tabular}

Figure 3C - Empirical Bayesian incidence rate (cases $/ 100,000$ inhabitants-year)
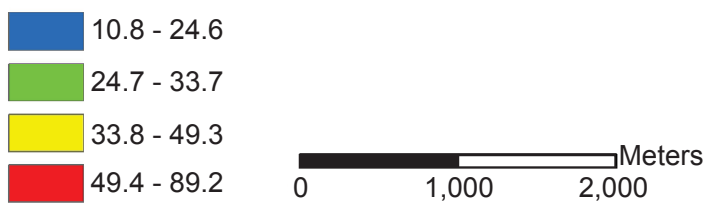

FIGURE 3 - A. Age standardized incidence rates of HVL by urban census sectors. B. Urban census sectors and the year of the occurrence of the first HVL cases inside them. C. Local empirical Bayesian incidence rates of HVL by urban census sectors. Adamantina, State of São Paulo, Brazil, $2004-2011$. HVL: human visceral leishmaniasis. 


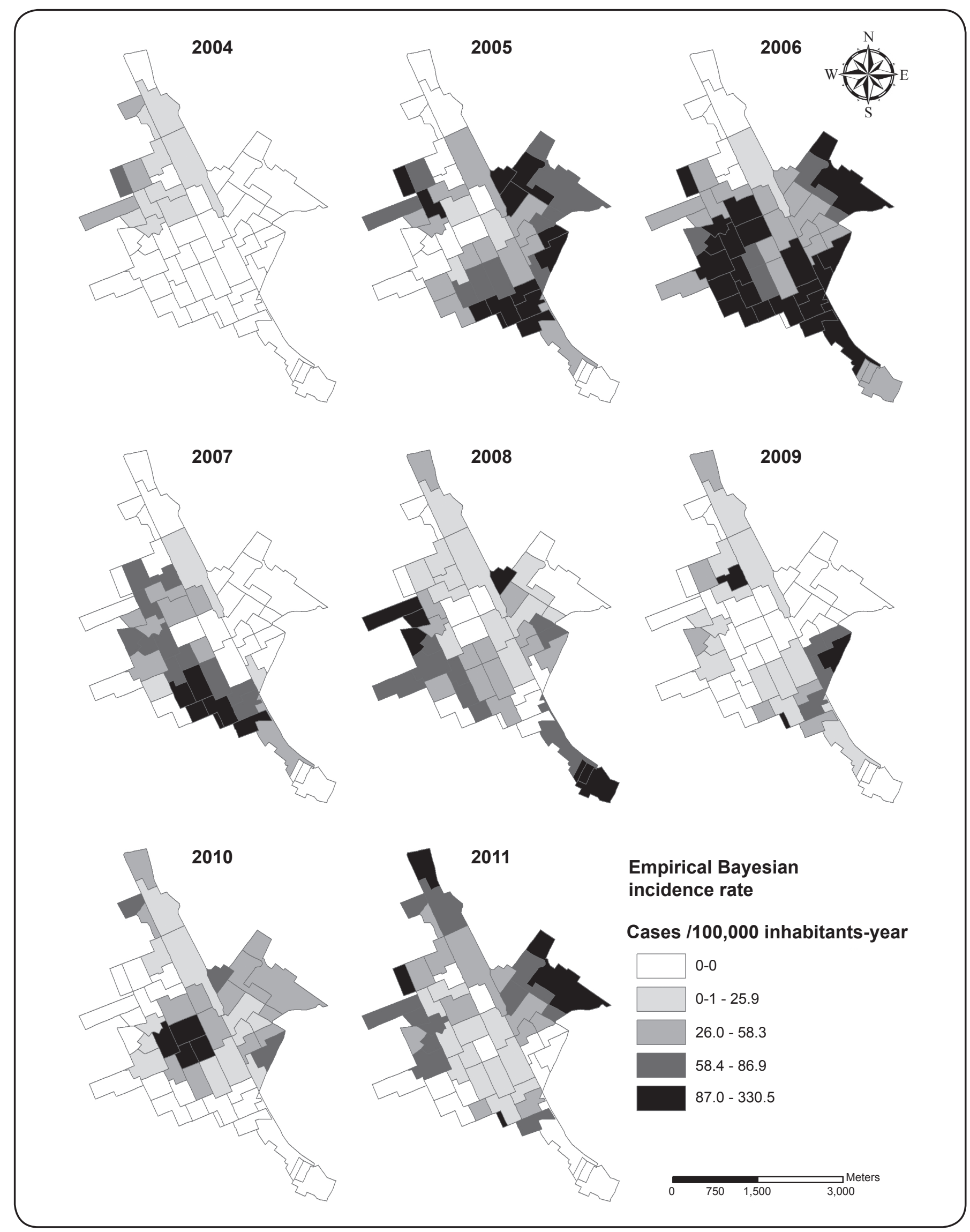

FIGURE 4 - Local empirical Bayesian incidence rates of HVL, by urban census sectors and year, in Adamantina, State of São Paulo, Brazil, $2004-2011$. HVL: human visceral leishmaniasis. 


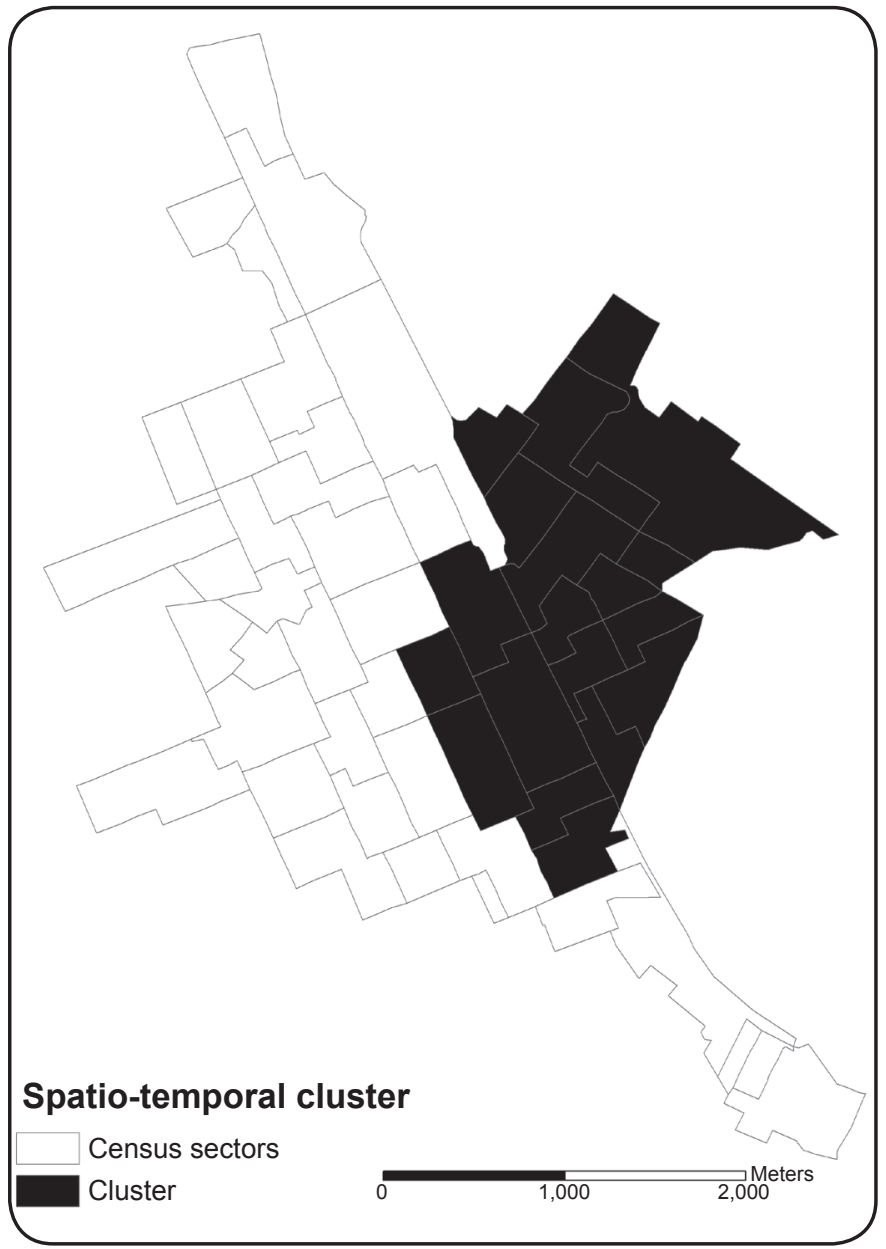

FIGURE 5 - Spatiotemporal cluster of cases of HVL from January 2005 to December 2006 in Adamantina, State of São Paulo, Brazil. HVL: human visceral leishmaniasis.

This evidence reinforces that the flow of people and goods by roads, principally in São Paulo, is an important factor that contributes to the dispersion of the disease, because the host cities of the microregions are poles of attraction and dispersion of these flows ${ }^{(5)(10)(11)(12)(13)}$. These findings could be used to prevent, or at least delay, the occurrence of the disease in areas without it, and might thus improve the surveillance and control measures in the host cities of the microregions.

In Adamantina, the age group of 0-4 years showed the highest incidence rate, which has been confirmed in other

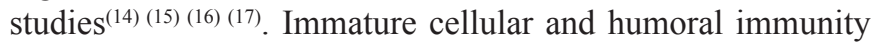
constitutes a risk factor that makes children more susceptible to infection ${ }^{(15)}$. In the Brazilian northeast region, infant susceptibility is also related to immunosuppression induced by malnutrition ${ }^{(15)}$, but this relationship is not decisive in Adamantina, as the city's human development index, in 2014, was equal to 0.812 , a value above the Brazilian average.

The 0-4-year-old age group also presented the highest mortality rate. The highest fatality rate was observed in the 40-59-year-old group, followed by the 0-4-year-old age group. These results differ from those of other studies ${ }^{(16)(18)(19)}$, wherein the $\geq 60$ age group demonstrated the highest mortality and fatality rates. Mortality rates would presumably be higher in this age group owing to a combination of HLV with other diseases already acquired, leading to adverse reactions caused by medicines ${ }^{(18)(19)}$. The high mortality rate and fatality rates in the 0-4-year-old age group in Adamantina could be a consequence of the highest incidence rate being observed in this group.

Human visceral leishmaniasis is a disease with a tendency towards male predilection ${ }^{(11)}$, and the male sex is noted as more susceptible owing to hormonal factors and situations of greater exposure to sandflies, such during agricultural projects, engineering projects, and in rural settlements ${ }^{(20)}$. However, this phenomenon was not verified in the present study, because there was a balance in the incidence between sexes, which was also observed in Birigui ${ }^{(16)}$.

The incidence curve for HVL in Adamantina shows that the HVL incidence rates were higher in the early years of the occurrence of the disease, but since 2007, there has been a downward trend in the number of reported cases, a situation similar to the one observed in the AR of Aracatuba ${ }^{(9)}$. The decrease in the incidence may be related to the implementation of the surveillance and control measures advocated by the National Plan for Surveillance and Control of Visceral Leishmaniasis $^{(10)(21)}$ and/or as a consequence of the expected cyclicity for this type of disease.

Regarding the spatial and temporal distribution of HVL autochthonous cases in the city, the first cases occurred in the peripheral census sectors that were not neighbors. Since then, the disease has expanded to census sectors with different socioeconomic characteristics, both in the periphery and in the central region, highlighting the spread of cases to the overall urban environment, a feature described in the study by Missawa and Borba ${ }^{(12)}$.

The socioeconomic and environmental characteristics of the urban census sectors of Adamantina apparently did not present a relationship with the distribution of the incidence rates and the Bayesian incidence rates. The census sectors with medium and high incidence rates had characteristics that favor the vector presence $^{(22)}$, independent of the socioeconomic status of the population living in these census sectors.

Although we did not identify spatial clusters throughout the study period, the spatiotemporal analysis identified a cluster of cases of HVL during the period from 2005 to 2006, when census sectors with high incidence were contiguous with others that also had a high incidence rate. This spatiotemporal cluster occurred during the period of time when Adamantina presented the highest incidence rates, i.e., 2005 and 2006.

This finding reinforces the transmissible characteristic of the disease in addition to the conditions of the environment that are generally associated with the occurrence and dissemination of $\mathrm{HVL}^{(12)}$. The area encompassed by the cluster, despite the various socioeconomic levels of its population, has similar characteristics, such as bordering the railway lines that have been deactivated for a long time and concentration of underbrush without maintenance, conditions that favor the breeding of the vector. In its larval stage, the vector develops in terrestrial environments rich in organic matter and moisture ${ }^{(22)}$. 
This study has some limitations that include the use of data obtained from secondary sources and the problems inherent to them, such as the possible underreporting of cases. Nevertheless, the proposed objectives were achieved so that it was possible to identify peaks of incidence in 2005 and 2006 and their stabilization from 2009 to 2011; in terms of spatial and temporal distribution, a cluster of high risk occurred during 2005 and 2006, which coincided with the commencement of the endemic in the city. We did not identify a relationship between the occurrence of HVL and the socioeconomic characteristics of the census sectors. Both sexes were equally affected by the disease, the highest incidence and mortality incidence rates occurred in children, and the highest fatality rate occurred among people aged 40-59 years. It is important to highlight that the use of the spatial analysis techniques helped us achieve the study objectives.

\section{CONFLICT OF INTEREST}

The authors declare that there is no conflict of interest.

\section{FINANCIAL SUPPORT}

Fundação de Amparo à Pesquisa do Estado de São Paulo, Process number 2010/20279-1 and Process number 2014/11342-2.

\section{REFERENCES}

1. Amora SSA, Bevilaqua CML, Feijó FMC, Oliveira PGM, Peixoto GCX, Sousa RN, et al. Sandflies (Psychodidae: Phlebotominae) survey in an urban transmission area of visceral leishmaniasis, Northeastern Brazil. Rev Bras Parasitol Vet 2010; 19:233-237.

2. Almeida AS, Werneck GL. Prediction of high-risk areas for visceral leishmaniasis using socioeconomic indicators and remote sensing data. Int J Health Geogr 2014; 13:13.

3. Ministério da Saúde (MS). Aspectos epidemiológicos. (Internet). Brasília: MS; 2014. (Acessed 2015 February 10). Available at: http://portalsaude.saude.gov.br/images/pdf/2014/setembro/09/LVCasos.pdf

4. Camargo-Neves VLF, Katz G, Rodas LAC, Poletto DW, Lage LC, Spínola RMF, et al. Utilização de ferramentas de análise espacial na vigilância epidemiológica de leishmaniose visceral americanaAraçatuba, São Paulo, Brasil, 1998-1999. Cad Saude Publica 2001; 17:1263-1267

5. Cardim MFM, Rodas LAC, Dibo MR, Guirado MM, Oliveira AM, Chiaravalloti-Neto F. Introdução e expansão da Leishmaniose visceral americana no estado de São Paulo, 1999 a 2011. Rev Saude Publica 2013; 47: 691-700.

6. Marshall R. Mapping disease and mortality rates using empirical Bayes estimators. J R Stat Soc Ser C Appl Stat 1991; 40:283-294.

7. Bailey T. Spatial statistics in health. Cad Saude Publica 2001; 17:1083-1098.
8. Kulldorff M, Heffernan R, Hartman J, Assunção R, Mostashari F. A space-time permutation scan statistic for disease outbreak detection. PLOS Med 2005; 2:216-224.

9. Centro de Vigilância Epidemiológica (CVE) Prof. Alexandre Vranjac (Internet). 2015 (Cited 2015 February 9). Available at http://cve.saude.sp.gov.br

10. Antonialli SAC, Torres TG, Paranhos Filho AC, Tolezano JE. Spatial analysis of American visceral leishmaniasis in Mato Grosso do Sul State, Central Brazil. J Infect 2007; 54:509-514.

11. Mestre GLC, Fontes CJF. A expansão da epidemia da leishmaniose visceral no estado de Mato Grosso, 1998-2005. Rev Soc Bras Med Trop 2007; 40:42-48.

12. Missawa NA, Borba JF. Leishmaniose visceral no município de Várzea Grande, Estado de Mato Grosso, no período de 1998 a 2007. Rev Soc Bras Med Trop 2009; 42:496-502.

13. Ximenes MFFM, Silva VPM, Queiroz PVS, Rego MM, Cortez ALM, Batista LMM, et al. Flebotomíneos (Díptera: Psychodidae) e Leishmanioses no Rio Grande do Norte, Nordeste do Brasil Reflexos do ambiente antrópico. Neotrop Entomol 2007; 36: 128-137.

14. Barata RA, Peixoto JC, Tanure A, Gomes ME, Apolinário EC, Bodevan EC, et al. Epidemiology of visceral leishmaniasis in a reemerging focus of intense transmission in Minas Gerais State, Brazil. Bio Med Res Int 2013; 2013:1-6.

15. Barbosa IR, Costa ICC. Clinical and epidemiological aspects of visceral leishmaniasis in children up to 15 years of age in Rio Grande do Norte state, Brazil. Sci Med 2013; 23:5-11.

16. Vieira CP, Oliveira AM, Colesbrusco RLA, Dibo MR, Guirado MM, Chiaravalloti Neto F. Temporal, spatial and spatiotemporal analysis of the occurrence of visceral leishmaniasis in humans in the City of Birigui, State of Sao Paulo, from 1999 to 2012. Rev Soc Bras Med Trop 2014; 47:350-358.

17. Xavier-Gomes LM, Costa WB, Prado PF, Oliveira-Campos M, Leite MTS. Características clínicas e epidemiológicas da leishmaniose visceral em crianças internadas em um hospital universitário de referência no norte de Minas Gerais, Brasil. Rev Bras Epidemiol 2009; 12:549-555.

18. Botelho ACA, Natal D. Primeira descrição epidemiológica da leishmaniose visceral em Campo Grande, Estado de Mato Grosso do Sul. Rev Soc Bras Med Trop 2009; 42:503-508.

19. Maldosso G, Fortaleza CM, Ribeiro NA, Cruz LL, Nogueira PA, Lindoso JAL. American Visceral Leishmaniasis: Factors associated with lethality in the state of São Paulo, Brazil. J Trop Med 2012; 2012:1-7.

20. Oliveira JM, Fernandes AC, Dorval MEC, Alves TP, Fernandes ID, Oshiro ET, et al. Mortalidade por leishmaniose visceral: aspectos clínicos e laboratoriais. Rev Soc Bras Med Trop 2010; 43:188-193.

21. Barata RA, Silva JCF, Silva JC, Almeida SN, Teixeira LAS, Dias ES. Controle da leishmaniose visceral no município de Porteirinha, estado de Minas Gerais, no período de 1998 a 2003. Rev Soc Bras Med Trop 2011; 44:386-388.

22. Ministério da Saúde, Secretaria de Vigilância em Saúde, Departamento de Vigilância Epidemiológica. Manual de vigilância e controle da leishmaniose visceral. Brasília: Editora do Ministério da Saúde; 2006. 